\title{
Synthesis of Cyclic Pentadepsipeptoids Analogues of Sansalvamide A by Combination of Ugi and Passerini Reactions
}

\section{Angélica de Fátima S. Barreto ${ }^{a}$, Otilie E. Vercillo ${ }^{a}$, Ludger A. Wessjohann ${ }^{b}$ and Carlos Kleber Z. Andrade ${ }^{\star a}$}

\author{
a Laboratório de Química Metodológica e Orgânica Sintética (LaQMOS), Instituto de Química, Universidade \\ de Brasília, CP-4478, 70910-970 Brasília-DF, Brasil and ${ }^{b}$ Department of Bioorganic Chemistry, Leibniz \\ Institute of Plant Biochemistry, Weinberg 3, 06120 Halle (Saale), Germany. \\ *ckleber@unb.br
}

Keywords: Ugi/Passerini reaction, peptoids and Sansalvamide A.

\section{INTRODUCTION}

Sansalvamide A (San A, 1) is a natural product isolated from a marine fungus (Fussarium ssp.). ${ }^{1}$ This cyclic depsipeptide exhibits a potent anticarcinogenic activity on multiple cancer cell lines. ${ }^{1 \mathrm{~b}}$

In continuing our research on the synthesis of peptoids with potential pharmacological activity, ${ }^{2}$ we decided to perform the synthesis of cyclic depsipeptoids analogues of San A (2a-b, Figure 1) based on a strategy previously developed in our group ${ }^{2 a}$ by combination of Ugi and Passerini reactions. To the best of our knowledge, the synthesis of cyclic depsipeptoids has not yet been explored.
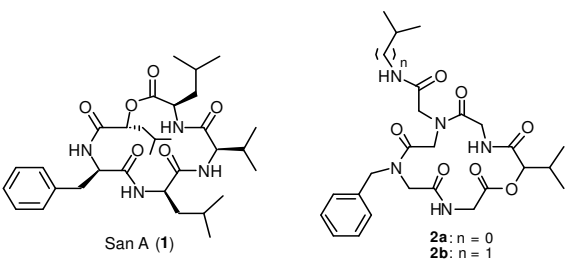

Figure 1. Sansalvamide A (1) and its depsipeptoid analogues (2).

\section{RESULTS AND DISCUSSION}

The aim of our study was to develop a general strategy for the synthesis of cyclic pentadepsipeptoids, as shown in Scheme 1. This strategy is based on: (a) formation of a peptoid via Ugi reaction; (b) ester hydrolysis; (c) formation of an acyclic tetradepsipeptoid scaffold in the Passerini reaction; (d) deprotection of the amine/acid and (e) a macrocyclization step via Ugi reaction.

Peptoid 7 was prepared in $81 \%$ yield by an Ugi 4component reaction (U-4CR) using benzylamine 3 , paraformaldehyde 4, N-Boc-glycine 5 and methyl isocyanoacetate 6 (Scheme 1) using microwave (MW) irradiation for $3 \mathrm{~min}\left(45^{\circ} \mathrm{C}, 150 \mathrm{~W}\right)$. Peptoid 7 was hydrolyzed after basic treatment $(\mathrm{LiOH}$, $\mathrm{THF} / \mathrm{H}_{2} \mathrm{O}$ ) to give the corresponding acid in quantitative yield. Acid $\mathbf{8}$ was employed in a Passerini reaction with isobutyraldehyde 9 and tert- butyl isocyanoacetate 10 , under $\mu \mathrm{W}$ irradiation for 4 min $\left(60{ }^{\circ} \mathrm{C}, 40 \mathrm{~W}\right)$ affording the acyclic tetradepsipeptoid 11 in $61 \%$ yield.

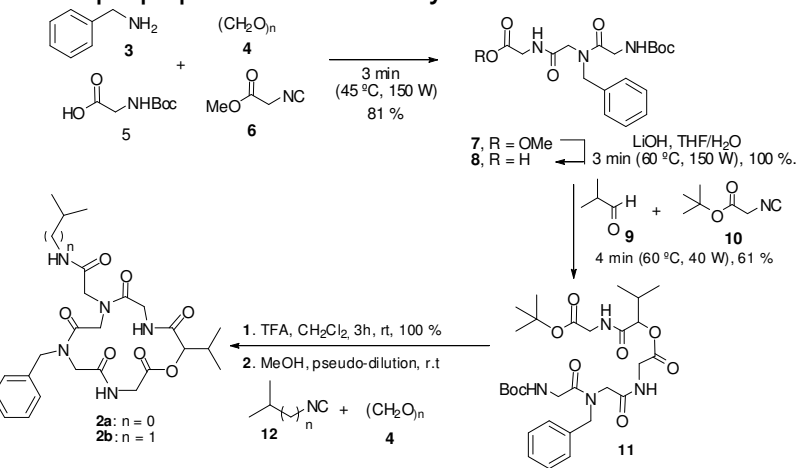

Scheme 1. Synthesis of cyclic pentadepsipeptoid analogues of San A (2a-b).

Removal of the Boc protecting group and ester hydrolysis were achieved after treatment of compound 11 with TFA in $\mathrm{CH}_{2} \mathrm{Cl}_{2}$ giving the amino acid in quantitative yield. Subsequent macrocyclization reactions involving Ugi threecomponent four-center reaction (U-3C4CR) using the obtained amino acid with paraformaldehyde and isopropyl/isobutyl isocyanide to give the target cyclic pentadepsipeptoid are in progress in our laboratory.

\section{CONCLUSION}

A fast and general synthetic route was developed for the synthesis of cyclic pentadepsipeptoids via consecutive multicomponent reactions.

\section{ACKNOWLEDGEMENTS}

IQ-UnB, Capes, CNPq and FINEP-CT INFRA no 0970/01.

\section{REFERENCES}

(a) Belofskv, G. N.; Jensen, P. R.; Fenical, W. T. Tetrahedron Lett. 1999, 40, 2913; (b) Vasko, R. C.; Rodriguez, R. A.; Cunningham, C. N.; Ardi, V. C.; Agard, D. A.; McAlpine, S. R. ACS Med. Chem. Lett. 2010, 1, 4.

2 (a) Vercillo, O. E.; Andrade, C. K. Z.; Wessjohann, L. A. Org. Lett. 2008 10, 205. (b) Barreto, A .F. S.; Vercillo, O. E.; Birkett, M. A.; Caulfied, J. C.; Wessjohann, L. A.; Andrade, C. K. Z. Org. Biom. Chem. 2011, DOI:10.1039/C1OB05471F; (c) Barreto, A F S ; Vercillo, O. E ; Andrade,

C. K. Z. J. Braz. Chem. Soc. 2011, 22, 462. 